\title{
NUEVO ENFOQUE Y PROPUESTAS EN LA EDUCACION SUPERIOR, BASADOS EN LA CONCEPCIÓN DE LA FORMACIÓN EN COMPETENCIAS PROFESIONALES
}

Ing Lucrecia Natalia Romero (*)

\section{RESUMEN:}

Este artículo propone compartir con otros docentes y la comunidad en general, una nueva mirada en la concepción enseñanzaaprendizaje dentro delámbito universitario.

PALABRAS CLAVES: enseñanza, aprendizaje significativo, construcción social del saber, competencias profesionales.

\section{DESARROLLO:}

El ejercicio profesional y las demandas actuales del mercado laboral, junto a los avances tecnológicos y la política económica social cambiante en forma global, exigen que los egresados de las Universidades se encuentren debidamente preparados para enfrentarlos. Las nuevas exigencias requieren una revisión permanente de la actividad docente y del proceso educativo.

En virtud de lo anteriormente expuesto es que decidí realizar un curso denominado "ENSENARR Y EVALUAR EN LA UNIVERSIDAD. REFLEXIONES Y PROPUESTAS BASADAS EN EL ENFOQUE DE COMPETENCIAS" dictado por las profesoras Susana Avolio De Cols y Silvia Paley de la Universidad de Buenos Aires (UBA) y en consecuencia, poder compartir con ustedes estas nuevas perspectivas en relación a la enseñanza-aprendizaje y las inte- rrelaciones de los componentes del proceso: docente, alumno y contenido.

Históricamente, la enseñanza superior, ha considerado al docente como el protagonista del acto educativo en relación a la importancia del enseñar o transmitir conocimientos a los alumnos, cuando en realidad la ecuación cerraría en el logro del aprendizaje significativo de los alumnos. Esto indicaría que el rol del alumno pasaría a ser fundamental, en la construcción del propio conocimiento.

Haciendo memoria, en nuestra vida de estudiantes y en autocrítica, como docente, se me representa la imagen del profesor preocupado en su clase magistral y en cumplir a rajatabla con la carga horaria de su materia, contemplando el dictado de todos los temas que figuran en el programa académico. Aquí llama a una reflexión: el rol del docente, en esta nueva concepción; sería despertar en los alumnos el interés en aprender los contenidos del programa del curso. Esto es un gran desafío ya que propone la reflexión de la práctica docente, al guiar al alumno en la construcción del conocimiento tal que este logre crear sus propios algoritmos en la resolución de problemas reales que pudieran presentarse en la profesión. El pensamiento crítico y reflexivo, junto a la resolución de problemas, se entrelazan y

(*) Universidad Nacional del Sur, Departamento de Ingeniería. Av. Alem 1257 (8000) Bahía Blanca. Provincia de Buenos Aires Telefax: 0291-4595157.lucrecia.romero@uns.edu.ar (cel 0291-154615609) 
refuerzan simultáneamente, propiciando un mayor compromiso del alumno frente a la tarea. Para ello, se plantea la revisión y cambio de la estructura de los planes de estudio y programas de las materias, promoviendo la relación entre contenidos y actividades en cada clase para lograr su integración.

Intuitivamente el docente está acostumbrado a que debe desarrollar en forma previa la teoría y la práctica como cierre de clase y aplicación. En este enfoque, se plantea el ejercicio complejo como hilo conductor de un mismo proceso, sin perder de vista que el alumno debe dominar simultáneamente, los contenidos básicos de la disciplina científica.

Otro factor a tener en cuenta es que si bien puede planificarse una clase, el docente deberá tener en cuenta que la misma se desarrollará en un determinado grupo social, circunstancia y ámbito académico, esto significa que cada grupo responderá de distinta manera, comprometiendo al docente en el refuerzo de las estrategias a adoptar para poder llevar a cabo el acto educativo.

Asimismo este enfoque privilegia y revaloriza el pensamiento y construcción del saber interdisciplinario, ya que prepara al alumno en la elaboración del conocimiento a través de la reflexión y el juicio crítico, en relación a los saberes que domina y trae aparejados en su matriz de aprendizaje.

Es sumamente importante la experiencia profesional del docente, $o$ en caso que no la tuviera su contacto con profesionales que ejerzan la profesión para acercarse a los re-

\section{REFERENCIAS BIBLIOGRÁFICAS:}

\footnotetext{
1. Apuntes del curso Módulo 3 .Unidad 1: "Enseñar y evaluar en la Universidad. Reflexiones y propuestas basadas en el enfoque de competencias" dictado por las profesoras Susana Avolio De Cols y Silvia Paley de la Universidad de Buenos Aires (UBA)

2. Psicología Educativa. Ausubel, D.P; Novak,J.D; Hanesian,H (1983) Ed. Trillas. México

3. Aprendizaje Escolar y Construcción del Conocimiento.
}

querimientos e innovaciones de la misma.

El constructivismo social es la teoría de aprendizaje que se asocia de la manera más adecuada con la formación basada en competencias, pero no descarta las bondades de las demás teorías de aprendizaje como herramientas disponibles para el docente en determinadas situaciones, como el conductismo para aprender determinados algoritmos.

EL APRENDIZAJE CONSISTE EN EL DESARROLLO DE LAS ESTRUCTURAS COGNITIVAS QUE SE PRODUCE MEDIANTE EL PROCESO DE APROPIACIÓN POR PARTE DEL SUJETO DEL LEGADO CULTURAL DE SU COMUNIDAD, DEL SABER DISCIPLINAR Y DE LOS SABERES PRACTICOS DE LA PROFESIÓN.(ref 1)

Los dos primeros módulos que desarrollé en el curso tienden a plantear la revisión de las propias prácticas y su posible readecuación en función de la enseñanza basada en competencias, pudiendo partir de la definición de enseñanza y aprendizaje en esta teoría, y como hemos dicho anteriormente la relación entre los componentes del proceso educativo. Los siguientes dos módulos a desarrollar proponen reestructurar el programa de la materia que se dicta, así como del fundamento de la materia y sus objetivos.

Es el comienzo de un LARGO CAMI$N O$ que propone el cambio de las prácticas áulicas y extráulicas, junto al desarrollo de las estrategias que permitan la implementación de este nuevo enfoque en el acto que nos convoca.

Coll,César (1994) Ed. Paidós. Buenos Aires

4. Construir Competencias En La Escuela. Perrenoud, P (1999) Ed. Dolmen. Santiago de Chile.

5. Teorias Cognitivas del Aprendizaje. Pozo, I. (1997) Ed. Morata. Madrid.

6. Aprendices y maestros la nueva cultura del aprendizaje. Pozo, Municio Ignacio.(1999) Ed Alianza. Madrid. 